\title{
Old anthropic dams, lacustrine deposits, and gullies from Șoldănești village
}

\author{
Mihai Ciprian Mărgărint, Mihai Niculiță, Silviu Doru, \\ Nicușor Necula \\ Department of Geography, Faculty of Geography and \\ Geology \\ Alexandru Ioan Cuza University of Iaşi \\ Iaşi, Romania \\ mihai.niculita@uaic.ro,margarint.ciprian@yahoo.com
}

\author{
Ionuț Cristea \\ Department of Geography \\ Faculty of Geography and History \\ Ştefan cel Mare University of Suceava \\ icristea@atlas.usv.ro
}

\section{INTRODUCTION}

A particular environmental feature of the northern part of Moldavian Plateau (NE Romania) is the large number of anthropic lakes along river courses [1, 2, 3]. Even more, due to climatic, hydrological, hydrogeological and geomorphological settings and human activities (dominated by an extensive agriculture) this characteristic was mentioned and mapped in written records and cartographic representations in many historical stages of the mentioned region humanization. The need for water supply have forced the inhabitants to build dams of various sizes along the entire river network. Over the time, many dams were abandoned, while others have been relocated with an impressive dynamic at historical time scale.

Due to their filling with sediments, many of them were abandoned during the time. Nowadays they represent a very specific anthropic fingerprint along almost every fluvial valley in this region. Recently LIDAR shading imagery allow us many possibilities to map every landforms associated with these old lakes: abandoned dams, lacustrine sediments, gullies, lacustrine terraces, alluvial fans etc.

For this field trip we selected a small hydrographic basin (Rogojeni), located in the center of Jijia catchment, in Şoldăneşti village, Botoşani County, where seven reservoirs (one active in the present and six abandoned) are present.

\section{II. ŞOLDĂNEŞTI RESERVOIRS}

Until nowadays, the spatial distribution of these historical generations of lakes was available only for certain periods (the case of historical maps) being characterized by numerous localization uncertainties and incompleteness. Analyzing recent high resolution LiDAR DEM images, we have performed an accurate inventory of abandoned dams. Using generating contour function of Global Mapper v.15.0 package, we have reconstructed an approximately spatial extension of corresponding lakes. Some of them have been recognized on old maps (topographic map form 1894, 1940, 1960, 1984), while many others have been identified and mapped for the first time in this work. Alongside this new cartographic representations and the possibilities to assess the dynamic this environmental factor, this historical inventory of old dams represent a useful database of lacustrine deposits of the studied region.

The reconstruction of the anthropic lakes network has many geoscientific relevance, concerning:

- paleoenvironmental reconstructions, by studying lacustrine sediments with multiproxy various analyses (particle size, pollen, phytolith, magnetic susceptibility, geochemistry, organic matter, and lead-210 and radiocarbon dating) available nowadays;

- anthropocene (recent) evolution and assessment of human activities on the environment, like erosion rate, agricultural practices, crop structure, related with representative hydro-meteorological past events.

\section{III. ŞOLDĂNEŞTI RESERVOIRS BOTTOM GULLIES}

The Northeastern Romania lowland is well known for its reservoir construction history and sedimentation all over the last 500 years. These reservoirs were in general small (under 1 million $\mathrm{m}^{3}$ ), shallow (4-5 $\mathrm{m}$ in depth, but with water levels of up to $3 \mathrm{~m}$ ) and frequently dry during the summer or winter. This anthropic intervention created a concentration of flow at high water discharges in the spillway area, which allowed the evolution of gullies on the flat lacustrine bottom.

From the six abandoned reservoirs located in the upper Rogojeni catchment, two present bottom reservoir gullies. These gullies are presented in Figs 1, 2 and 3. In Fig. 4 there are illustrated cross-section trough the reservoir bottom and through gully channels, while in Fig. 5 ERT scan are shown to illustrate the depth of reservoir sediment which are shown in Fig. 6.

\section{CONCLUSIONS}

The identification and mapping with a high spatial precision of the abandoned dams constitute important element in paleogeographic reconstruction, at least for the last centuries, due to sedimentary archives behind these dams. Future research of these valuable archive can improve the knowledge of environmental evolution and anthropic impact at regional scale. 
New technologies like ERT scanning complete the classical ones in validation of the topographical reconstruction of the landforms using high resolution DEM's.

Many other applications of the LIDAR DEMs will be used for assessing and mapping other anthropic landforms which were difficult to map until the present.

The erosional presented patterns are related to the potential of the reservoir bottoms to become erosional hot spots, showing the potential of the acceleration of erosional processes, with theirs negative consequences.

\section{ACKNOWLEDGMENT}

We are grateful to Prut-Bârlad Water Administration who provided us with the LIDAR data. We have used the computational facilities given by the infrastructure provided
$26.92^{\circ} \mathrm{E}$ through the POSCCE-O 2.2.1, SMIS-CSNR 13984-901, No. 257/28.09.2010 Project, CERNESIM (L4).

\section{REFERENCES}

[1] M.C. Mărgărint and M. Niculiță, "Using high resolution LIDAR DEM to reconstruct historical network of lakes and wetlands in the Northern part of the Moldavian Plateau, NE Romania”, Georeview, vol. 26, no. 2, pp. 59, 2016. http://dx.doi.org/10.4316/GEOREVIEW.2016.0.0.336

[2] M. Niculiță, M.C. Mărgărint, and P. Tarolli, "Historical reservoir construction: potential hotspot of anthropogenic induced sediments in lowland Northeastern Romania”, Geophysical Research Abstracts, vol. 19, EGU2017-11922-1, 2017.

[3] M.C. Mărgărint, M. Niculiță, A. Nemeth, and I. Cristea, "Topographic and depositional signature of old anthropic lakes in northern part of the Moldavian Plateau (NE Romania)", Geophysical Research Abstracts, vol. 19, EGU2017-12206-1, 2017.

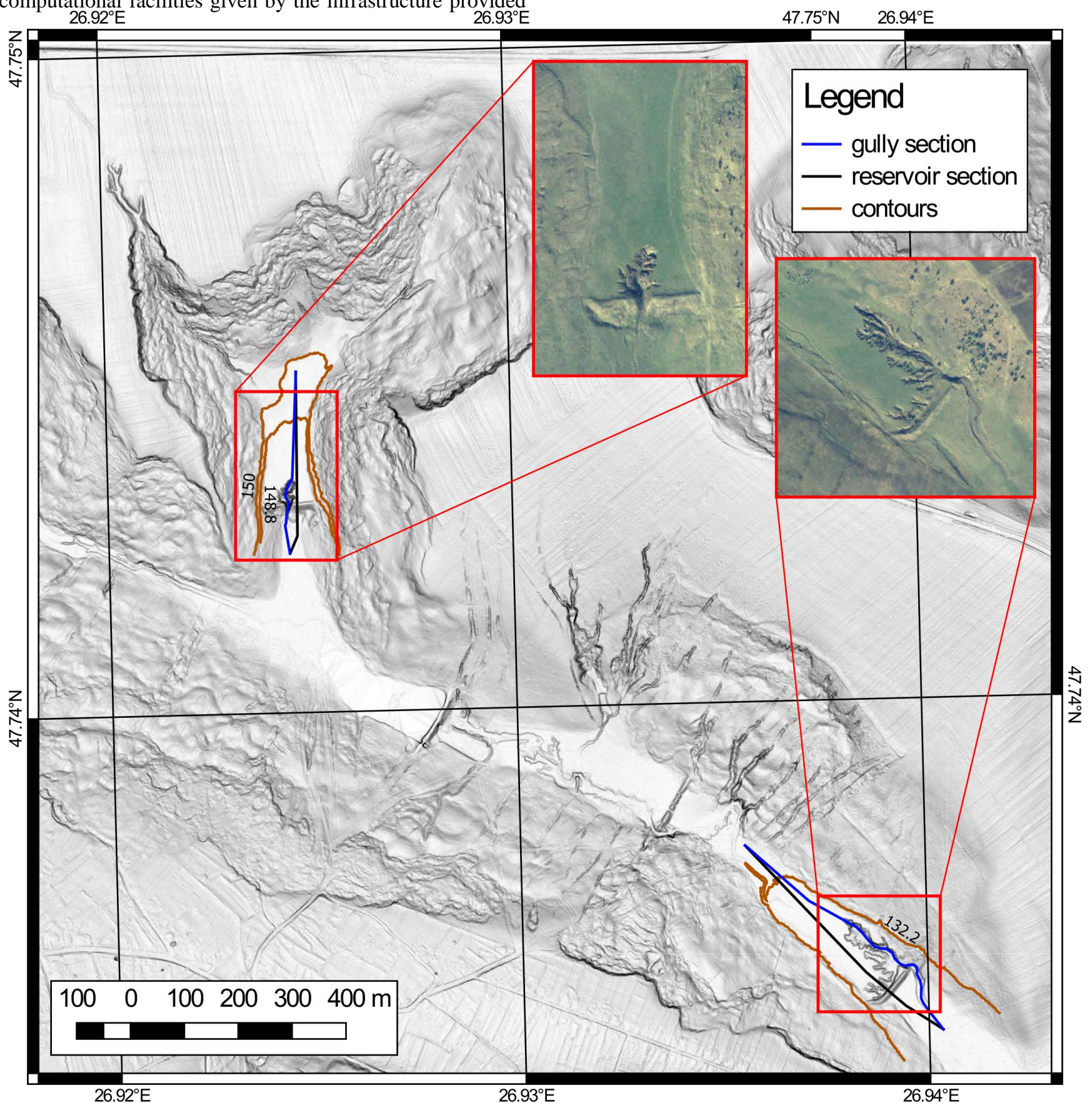

Fig. 1. Overview of the Șoldănești reservoirs, dams and gullies on LiDAR shading 


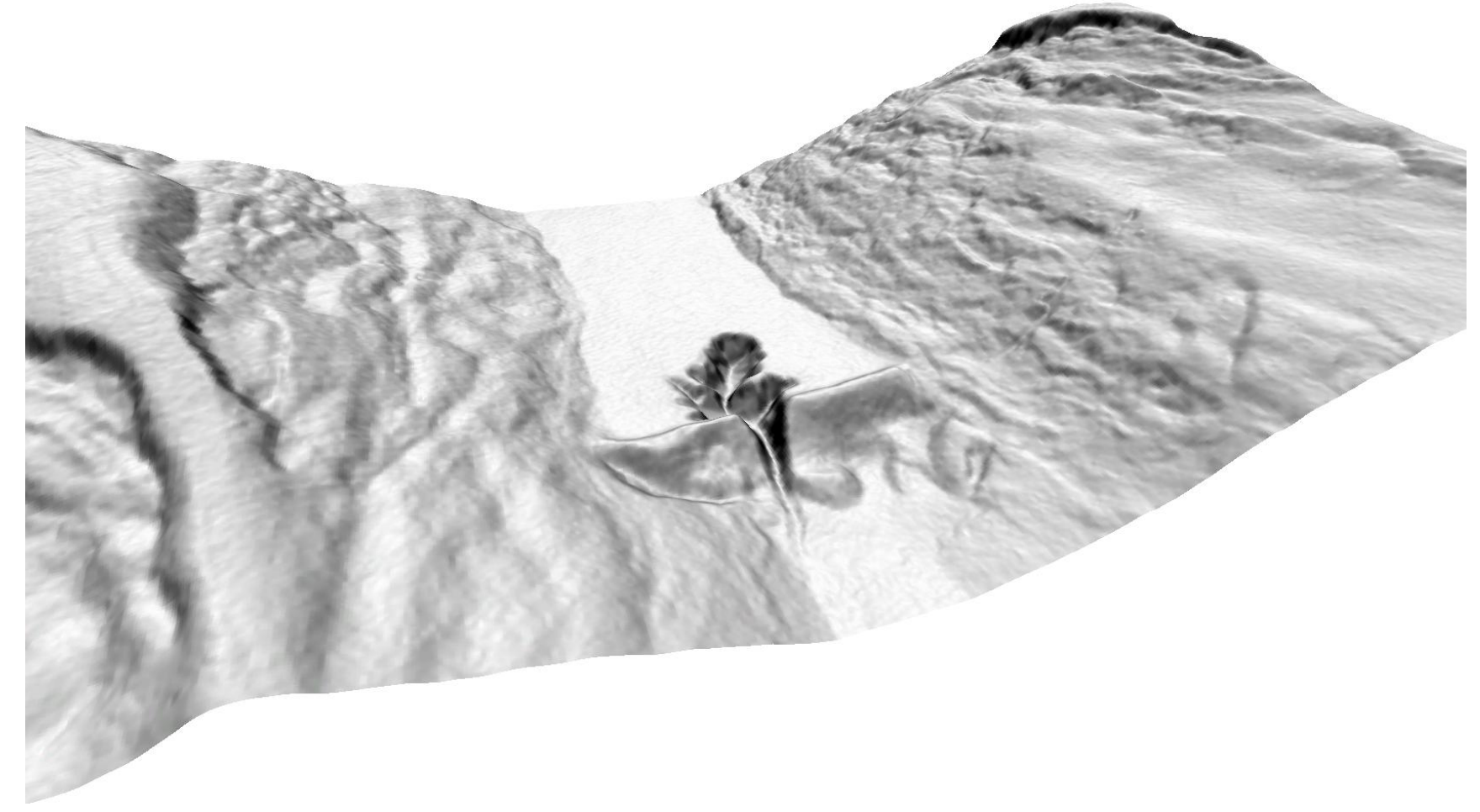

Fig. 2. 3D view of LiDAR shading for the northern gully and reservoir.

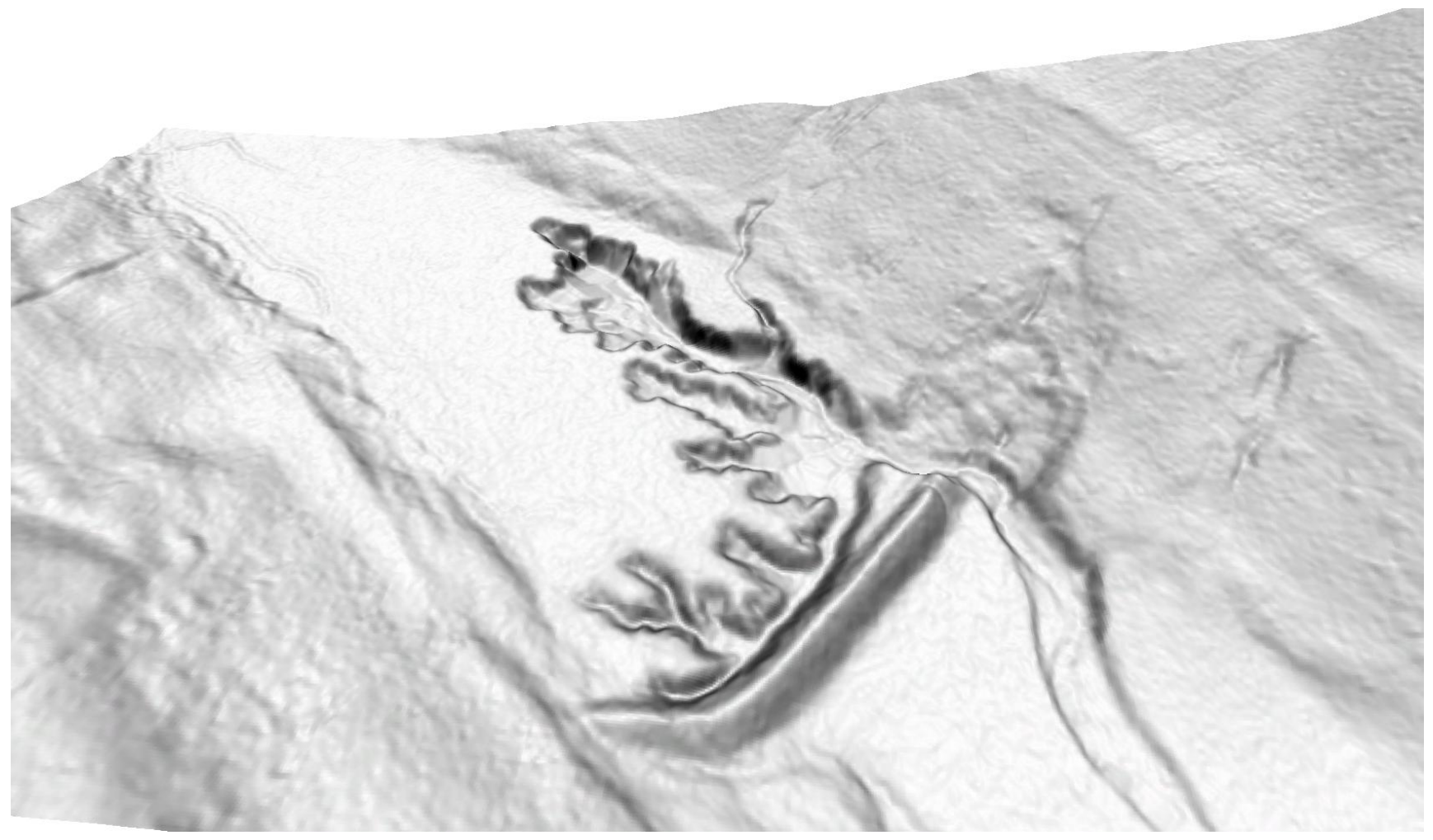

Fig. 3. 3D view of LiDAR shading for the southern gully and reservoir. 

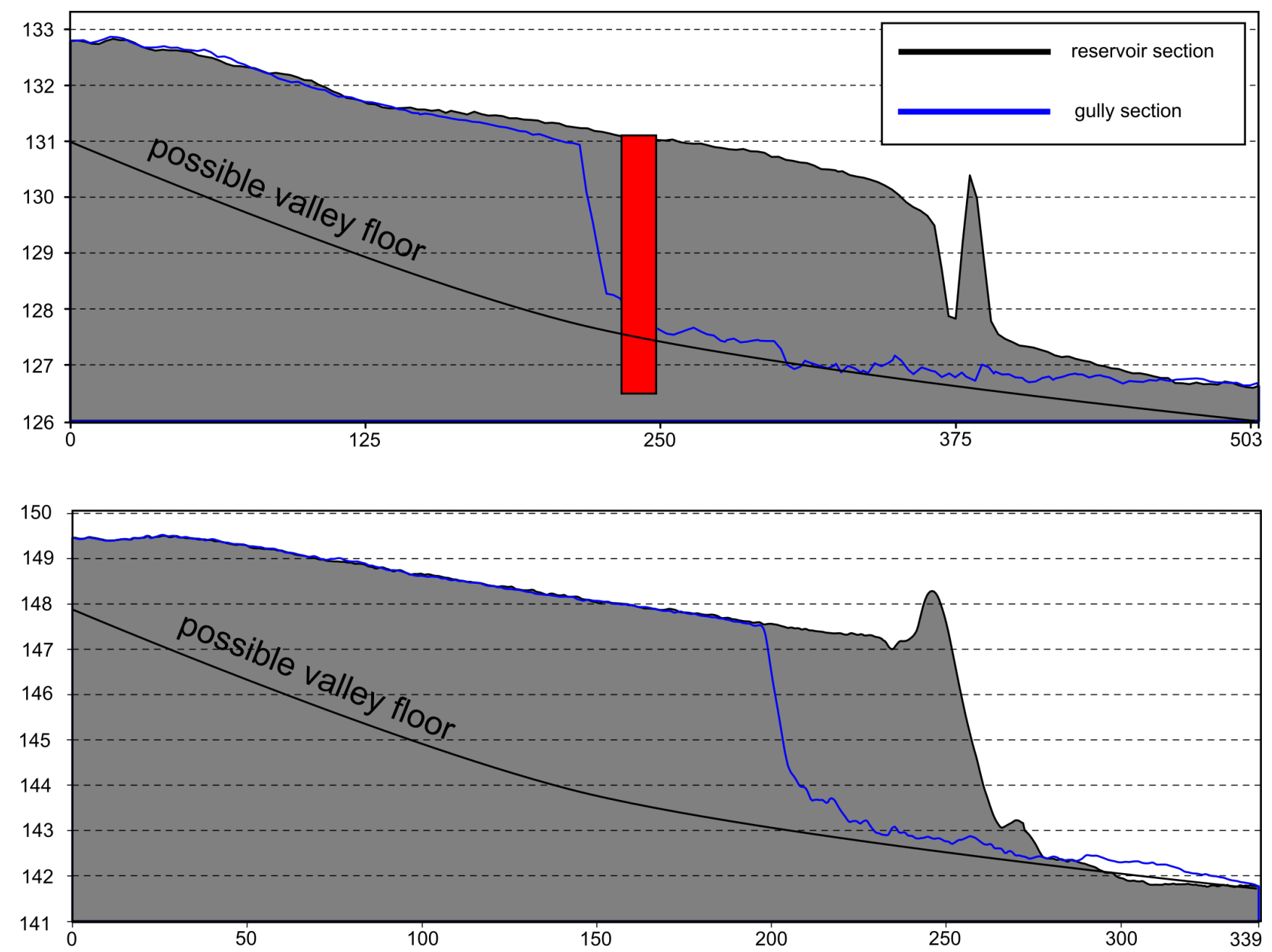

Fig. 4. Topographic section through the reservoirs (black line) and trough the bottom gullies (blue line) (upper section is for the southern gully, bottom section is for the northern gully).

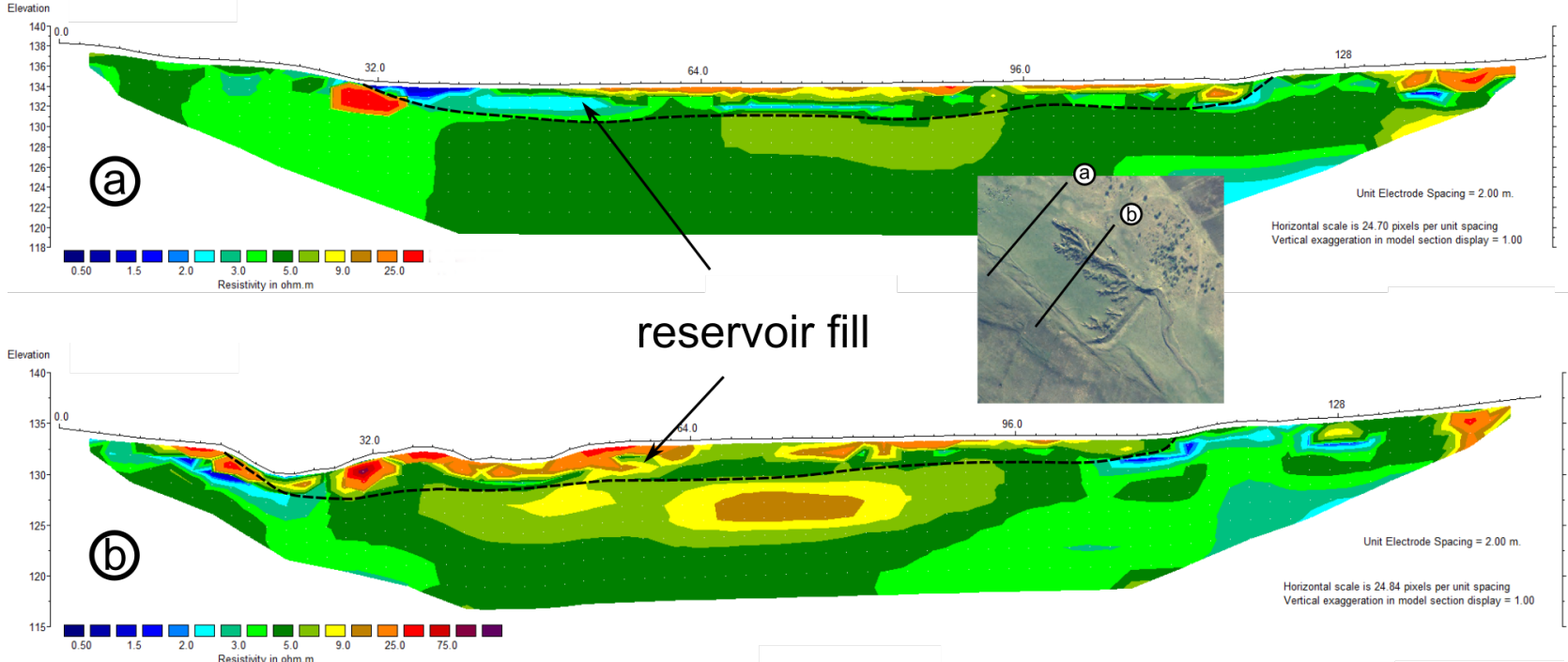

Fig. 5. Southern reservoir stratigraphy interpreted from 2D ERT scans. 


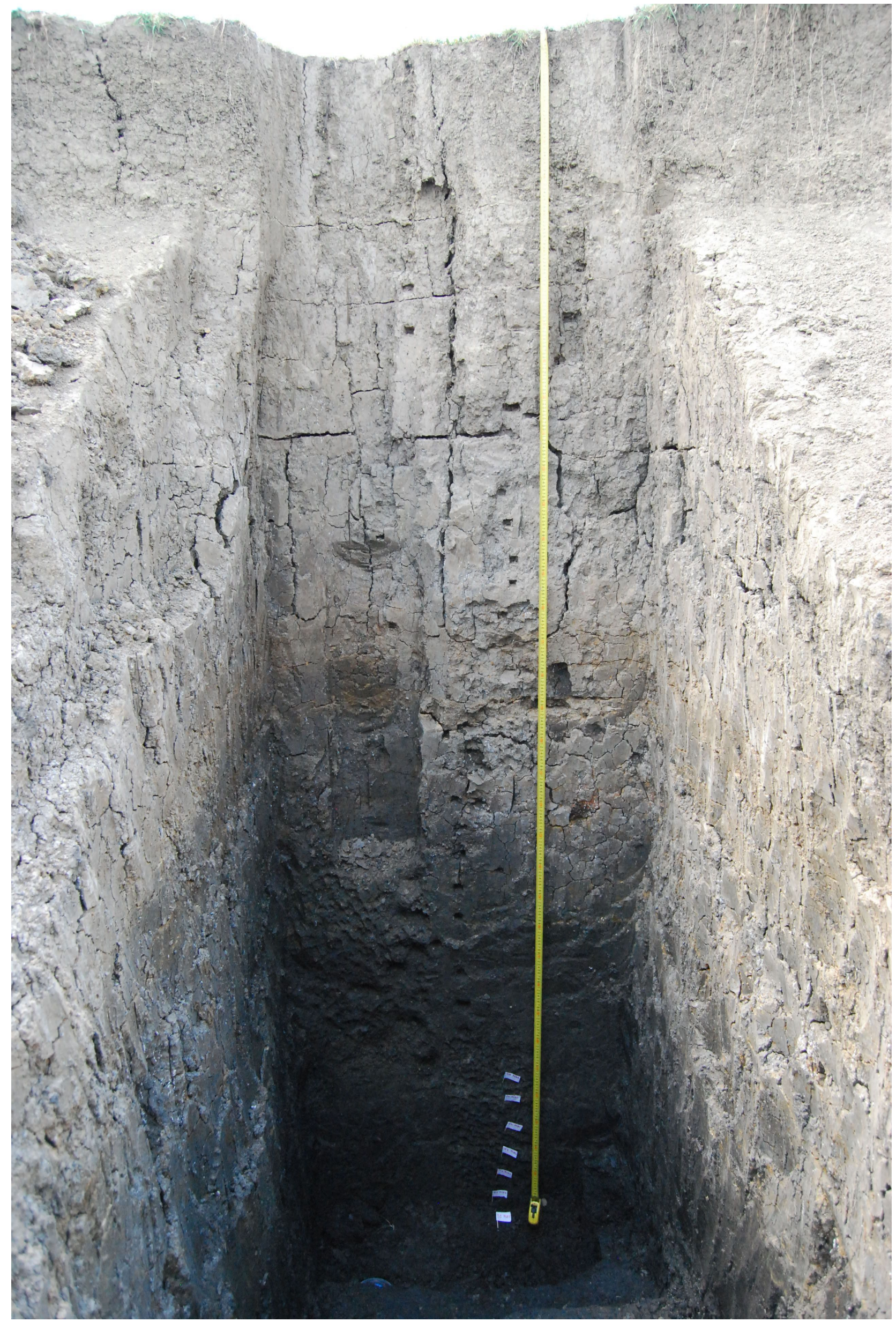

Fig. 6. Sediment column of the southern reservoir (the location and depth of the column is indicated in Fig. 4). 